\title{
Agora: Practice Theory and International Relations
}

We are delighted to present this third Agora with Global Constitutionalism. As with the previous two agora publications, we choose the specific format of an agora - representing a central public square or a market place - in order to provide a virtual public stage. As such, an agora allows for presentation of and critical engagement with a recent outstanding publication which promises to make a mark for those interested in themes of Global Constitutionalism. Following the two previously discussed subject issues of 'contested multilateralism' (Global Constitutionalism 2016) and 'The Internationalists' (Global Constitutionalism 2018), the present agora focuses on the recent book by Mervyn Frost and Silvya Lechner titled Practice Theory and International Relations ${ }^{1}$ (hereafter: Practice Theory). Practice Theory has been conceived against the backdrop of the practice literature in international relations (IR) theory, international political theory (IPT) and Political Philosophy. By addressing the concept of 'practice' the authors both critically scrutinise the arguable 'practice turn' in IR theory (compare the kick-off by Adler and Pouliot's 2012 book $)^{2}$ and propose a distinct approach to practice theory on their own. As this agora's critical engagements highlight, Practice Theory clearly hits a nerve.

Practice Theory offers a most remarkable theoretical advance based on a concise theoretical project and in addition it provides a welcome advance on central questions in the field of practice theory. In doing so, the authors offer a genuine and often quite critical contribution to the ongoing cuttingedge theoretical debate. In sum, Practice Theory achieves developing a theoretical framework which succeeds in linking practice and normativity in a way much of the practice literature lacks. It takes off from a conceptual standpoint which has been appreciated by other IR theorists and who work on either practice or normativity but have not quite 'got there' yet. The book's novel contribution lies in distinguishing micro- and macro-practices and explaining why this matters (e.g. with reference to

1 M Frost and S Lechner, Practice Theory and International Relations (Cambridge University Press, Cambridge, 2018).

2 E Adler and V Pouliot (eds), International Practices (Cambridge University Press, Cambridge, 2012). 
the IR literature on Bourdieu and on Foucault which either prioritises micro-practices, or mistakes them for macro-practices, or both), on the one hand, and, by theorising the internal and external meanings of practices, thereby offering a conceptual access point for socially constructed, societally or constitutionally constituted and politically challenged normativity (i.e. with reference to Hegel, Wittgenstein, Oakeshott and Rawls, instead), on the other. Apart from targeting some of uncomfortable loose ends that 'practice turners' ignore (see especially Hofius in this issue), the authors in this Agora raise critiques of the practice turn from numerous perspectives, including Constructivism, the English School, scientific realism, and norms research. Notably, the latter includes interdisciplinary engagement beyond the IR theory community, which are of interest to international law and global constitutionalism, as this agora highlights quite convincingly.

The central point of the proposed neo-Hegelian reference is the distinction between the 'internal' and 'external' dimension of practice: not everything can be understood through the empirical method of mere observation. From the vantage point of the 'practice turn' in IR theory, the proposed framework of what the authors call a 'neo-Hegelian' understanding of practice theory is genuine and welcome. And in light of an interest in sociological theory and a preference to engage with research methodologies as opposed to normative and ethical issues in global politics, the framework fills a gap in IR theory. Whether and how this is appreciated by the experts, remains to be demonstrated. To that end, we invited this agora's discussion.

Practice Theory was presented and discussed at an 'author meets critics' round table which was held at this year's International Studies Association conference in Toronto, Ontario. ${ }^{3}$ Most of this agora's contributors were also directly engaging with the authors at the Toronto round table. They have subsequently been invited to elaborate on their critical engagements and submit them in writing with GlobCon. The contestants offer critical comments from political science and international relations (IR) theory (compare, e.g., the contributions by Hellmann, Hofius, Kusterman and Skoniezcny in this issue) as well as from international law and IR theory (compare Stappert, in this issue). The agora brings together considerable diversity with regard to their respective methodological preference and philosophical background expertise. The result offers a fascinating in-depth engagement with philosophical and methodological underpinnings of

3 60th International Studies Association Conference, 27-30 March 2019, Toronto, details at: <https://www.isanet.org/Conferences/Toronto-2019>. 
practice theory brought onto a single 'stage' by the agora format. As a take-home from this agora, we note that the 'practice turn' is not only alive and well, it actually matters, as this agora's contestants elaborate in fascinating detail in their respective critical engagements.

The Editors 